\title{
Complex diagnostics of early gastric cancer associated with Helicobacter pylori infection in the adult population of Siberia
}

\author{
Smirnova Olga ${ }^{*}$, Sinyakov Aleksandr ${ }^{(\infty}$
}

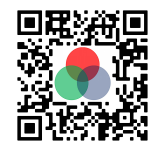

Use your smartphone to scan this QR code and download this article

Federal Research Center "Krasnoyarsk Scientific Center of the Siberian Branch of the Russian Academy of Sciences" Scientific Research Institute of Medical Problems of the North

\section{Correspondence}

Smirnova Olga, Federal Research Center "Krasnoyarsk Scientific Center of the Siberian Branch of the Russian Academy of Sciences" Scientific Research Institute of Medical Problems of the North

Email: ovsmirnova71@mail.ru

\section{History}

- Received: Oct 07, 2021

- Accepted: Nov 16, 2021

- Published: Dec 29, 2021

DOI : 10.15419/bmrat.v8i12.709

\section{Check for updates}

\section{Copyright}

(c) Biomedpress. This is an openaccess article distributed under the terms of the Creative Commons Attribution 4.0 International license.

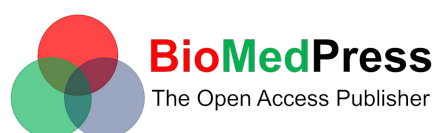

\begin{abstract}
Background: Most researchers point to a decrease in immunity indicators in patients with gastric cancer. At the same time, there are ambiguous interactions between tumor growth and the functioning of the immune system. Identifying gastric cancer patients at an early and curable stage of the disease is essential if the mortality rates for this disease are to decrease. The only way to prevent the development of gastric cancer is the potential reversibility of precancerous changes in the gastric mucosa. The early diagnosis of chronic atrophic gastritis is a preventive measure and it should be carried out in both the presence and absence of the symptoms of dyspepsia. Methods: A total of 299 blood samples were collected, inclusive of 98 gastric cancer patients, 104 healthy controls, and 97 patients with chronic atrophic gastritis. An evaluation of spontaneous and induced chemiluminescence (CL) was carried out for 90 minutes using a 36-channel biochemiluminometer "BLM - 3607" (Russia), and an Olympus fluorescence microscope was used for cell counting. Interpretation \& conclusions: Our study showed the significance of the parameters, specifically the maximum intensity of spontaneous (Ispont) and induced chemiluminescence (lindus) of the neutrophils and monocytes, the indices of granulocytic and monocytic phagocytosis, malondialdehyde (MDA), and the ratio of the activity of the enzyme superoxide dismutase to glutathione / CAT ratio superoxide dismutase to glutathione peroxidase (SOD / GPO) in the diagnosis of early gastric cancer. Using the threshold values of the proposed criteria in the screening of the adult population, it is possible to form a group that is at a high risk of developing early gastric cancer and to achieve a decrease in the mortality and disability rates in the population of Siberia. This is as well as allowing for the choosing of a more personalized therapy for the patients at a high risk of developing early gastric cancer.
\end{abstract}

Key words: Adenocarcinoma, chemiluminescent activity, chronic atrophic gastritis, early cancer, early diagnosis, enzyme activity, monocytes

\section{INTRODUCTION}

Gastric cancer (stomach cancer) is the most common malignant neoplasm of this organ ${ }^{1,2}$. Although the incidence of stomach cancer is declining, it is the fifth most common malignant neoplasm worldwide. In 2012, 952,000 new cases and 723,000 deaths were diagnosed $^{3,4}$. Among the oncological diseases leading to death, gastric cancer is in second place ${ }^{5,6}$. Adenocarcinoma of the stomach tends to develop in any part of the stomach and spread to other organs, especially the esophagus, lungs, and liver. Metastases occur in $80-90 \%$ of patients with gastric cancer ${ }^{7}$, and the six-month survival rate is present in $65 \%$ of cases where there is the early diagnosis of the disease and less than $15 \%$ in the later stages of the process. On average, the highest survival rate for stomach cancer is in Japan at $53 \%{ }^{8}$. It does not exceed $15-20 \%$ in other countries. This disease is more often diagnosed in middle-aged men. In the early stages, the disease is asymptomatic. The primary diagnosis reveals a tumor in the $3-4$ stages of development ${ }^{9,10}$. It is also believed that Helicobacter pylori infection triggers a reaction chain leading to chronic atrophic gastritis (CAG) and a further degeneration into stomach cancer $^{11,12}$. It is considered to be statistically proven that those infected with this bacterium have a significantly higher risk of developing stomach cancer ${ }^{13,14}$. The only way to prevent the development of gastric cancer is due to the potential reversibility of the precancerous changes in the gastric mucosa. The early diagnosis of chronic atrophic gastritis is a preventive measure and should be carried out both in the presence and absence of symptoms of dyspepsia ${ }^{15,16}$. The screening test should be highly effective while being safe and convenient for patients ${ }^{17}$.

In this regard, the purpose of our work was to evaluate the clinical-anamnestic, serological, immunological, and biochemical tests used for the early diagnosis of gastric cancer associated with Helicobacter pylori in- 
fection in the adult population of Siberia.

\section{METHODS}

This study was carried out with the permission of the Ethics Committee of the Research Institute in the Ministry of Health of the Federal Research Center of the KSC of the SB RAS, as well as with the permission of the Ethics Committee of the Krasnoyarsk Regional Clinical Oncological Dispensary named after A.I. Kryzhanovsky. This study included middle-aged patients (45 to 59 years old with a mean age $53 \pm$ 5.7). All patients had complaints of epigastric pain and/or dyspepsia. In addition, all patients had a history of stomach diseases (chronic gastritis and gastric ulcers). The clinical examination of the men with chronic atrophic gastritis was carried out in the therapeutic department of the Scientific Research Institute of the Ministry of Health of the Federal Research Center of the KSC SB RAS. The clinical examination of the patients with stomach cancer was carried out in the Krasnoyarsk Regional Clinical Oncological Dispensary named after the Kryzhanovsky Department of Oncoabdominal Surgery named after N.A. Rykovanov.

The control group consisted of 104 practically healthy middle-aged blood donors ( $48.7 \pm 3.9$ years) without gastroenterological complaints and a gastroenterological history without changes in the coolant. This study did not include patients with HIV infection, hepatitis, tuberculosis, gastric ulcer, and either concomitant acute or chronic diseases in the exacerbation phase. This study also did not include patients who refused to participate in a scientific study. The comparison group included 97 patients with chronic atrophic gastritis $(47.2 \pm 4.9$ years). The diagnosis was made by a gastroenterologist during an examination for the first time based on the epidemiological and clinical data. This was confirmed by a serological examination of the pepsinogens using an ELISA and the atrophic changes in the mucous membrane of the greater and lesser curvature of the stomach body using the modified Sydney classification for fibroesophagogastroduodenoscopy. The exclusion criteria were similar to those for the control group.

The group of patients with early gastric cancer consisted of 98 patients in the initial stages of the disease. The average age of the patients with gastric cancer admitted to the department was $49.2 \pm 4.9$ years. The diagnosis was made based on the clinical, anamnestic, laboratory, and instrumental data by an oncologist. In all groups, the presence of $H$. pylori was detected using an ELISA by determining the titer of specific antibodies in relation to the H. pylori CagA antigen. Antibody titers of 30 EIU or more were considered to be a positive result and those that were less than 30 EIU were considered to be a negative result for H. pylori ${ }^{18}$.

An evaluation using spontaneous and induced chemiluminescence (CL) was carried out for 90 minutes using a 36-channel biochemiluminometer "BLM 3607" (Russia) while an Olympus fluorescence microscope was used for cell counting. The time taken to reach the maximum (Tmax), maximum value (Imax) of $\mathrm{CL}$, and the area of the curve (S) were determined. To enhance the chemiluminescence, an activator, luminol, was used. Zymosan was used as an inducer. Phagocytosis was assessed using a Beckman Coulter cytomyc FC 500 flow cytometer.

To study the processes of lipid peroxidation and the factors of the antioxidant defense system (LPOAOD), the concentrations of primary (diene conjugates) and final (malonic dialdehyde) lipid peroxidation products formed in the various stages of the free radical chain reaction were studied. The AOD activity was judged by the content of its main components (superoxide dismutase, catalase, glutathione Stransferase, glutathione peroxidase, and ceruloplasmin). A Varyan Cary Eclipse spectrofluorimeter was used to study the LPO-AOD system.

Based on the results of this research, a database was formed using the MS Excel spreadsheet package. Statistical data processing was carried out using the Statistica 10.0 software package (StatSoft, USA). The analysis of the correspondence between the distribution type of feature and the law of normal distribution was carried out using the Shapiro - Wilk test. When describing the sample, the median $(\mathrm{Me})$ and interquartile range of the percentiles $(\mathrm{C} 25-\mathrm{C} 75)$ was calculated. The significance of the differences between the indices of the independent samples was assessed using the Mann - Whitney test $(\mathrm{p}<0.05)$.

\section{RESULTS}

During the screening study, it was found that all patients with early gastric cancer over the age of $45 \mathrm{had}$ complaints of pain in the epigastric region and/or dyspepsia, and a history of stomach diseases such as chronic atrophic gastritis, gastric ulcer, stomach polyps, etc. $(\mathrm{p}<0.05)$ The serological diagnostics of patients with early gastric cancer revealed contamination with Helicobacter pylori bacteria in $100 \%$ of cases $(\mathrm{p}<0.05)$, a decrease in the PGI level of less than 25 $\mu \mathrm{g} / \mathrm{l}$, and a PGI/PGII ratio of less than three in most cases $(p<0.05)$. Half of the patients had dysplasia of the gastric mucosa $(\mathrm{p}<0.05)$.

In the study of the phagocytic link in healthy blood donors, patients with chronic atrophic gastritis, and 
Table 1: Diagnostics of early gastric cancer associated with Helicobacter pylori infection

\begin{tabular}{lccc}
\hline Indicators & $\begin{array}{c}\text { Control group } \\
\mathbf{N}=\mathbf{1 0 4}\end{array}$ & Patients with CAG & Patients with GC \\
& $\mathbf{N}=\mathbf{9 7}$ & $\mathbf{N}=\mathbf{9 8}$ \\
\hline Ispont (neutrophils) c.u. & 19133 & 22083 & 17825 \\
& {$[3054-27134]$} & {$[3047-41528]$} & {$[15789-17831]$} \\
Iindust (neutrophils) c.u. & 34940 & $\mathrm{p}_{1-2}=0.03$ & $\mathrm{p}_{1-3}=0.03 ; \mathrm{p}_{2-3}=0.03$ \\
& {$[10488-41588]$} & 50231 & 24987 \\
& & {$[21341-71041]$} & {$[17345-30000]$} \\
Granulocytic phagocytosis & $75 \% \pm 5 \%$ & $\mathrm{p}_{1-2}=0.02$ & $\mathrm{p}_{1-3}=0.04 ; \mathrm{p}_{2-3}=0.04$ \\
& & $56 \% \pm 7 \%$ & $30 \% \pm 6 \%$ \\
Ispont (monocytes) ) c.u. & 2631 & $\mathrm{p}_{1-2}=0.02$ & $\mathrm{p}_{1-3}=0.01 ; \mathrm{p}_{2-3}=0.03$ \\
& {$[1100-3143]$} & 5123 & 419 \\
Iinduce (monocytes) c.u. & & {$[5732-13456]$} & {$[276-454]$} \\
& 7983 & $\mathrm{p}_{1-2}=0.02$ & $\mathrm{p}_{1-3}=0.01 ; \mathrm{p}_{2-3}=0.01$ \\
& {$[4789-11345]$} & 11985 & 962 \\
\hline & & {$[8932-16789]$} & {$[785-1186]$}
\end{tabular}

Note: $\mathbf{p}_{1-2}$ : statistically significant differences between the group of CAG patients and the control group, $\mathbf{p}_{1-3}:$ statistically significant differences between the group of patients with GC and the control group, $\mathbf{p}_{2-3}$ : statistically significant differences between the group of patients with CAG and the group of patients with GC.

stomach cancer, the following regularities were revealed. When studying the maximum intensity of spontaneous and induced chemiluminescence (CL) of the neutrophils in the patients with chronic atrophic gastritis, this indicator increased relative to the control group and the group of patients with early gastric cancer $\left(\mathrm{p}_{1-2}=0.03 ; \mathrm{p}_{1-3}=0.03\right)$ (Table 1). In patients with early gastric cancer, there was a decrease in the maximum intensity of the spontaneous and induced chemiluminescence (CL) of the neutrophils relative to the control group $\left(\mathrm{p}_{2-3}=0.03 ; \mathrm{p}_{2-3}=\right.$ $0.04)$. When studying the phagocytic activity of the neutrophilic granulocytes in patients with chronic atrophic gastritis and early gastric cancer, there was a decrease in the number of phagocytic neutrophils relative to the control group.

When studying the phagocytic link of immunity, it was found that all patients with early gastric cancer were diagnosed with having the indicators of the maximum intensity of spontaneous CL of neutrophils from 17831 c.u. and below, and with induced CL from 30,000 c.u. and below. The phagocytic activity of the neutrophilic granulocytes in patients with early gastric cancer was $36 \%$ and lower.

When studying the maximum intensity of the spontaneous and induced chemiluminescence (CL) of the monocytes in patients with chronic atrophic gastritis, this indicator increased compared to the control group and early gastric cancer $\left(\mathrm{p}_{1-2}=0.02 ; \mathrm{p}_{1-3}=\right.$ 0.01 ). In early gastric cancer, there was a decrease in the maximum intensity of the spontaneous and induced chemiluminescence (CL) of the monocytes relative to the control group $\left(\mathrm{p}_{2-3}=0.01 ; \mathrm{p}_{2-3}=0.003\right)$. When studying the phagocytic activity of the monocytes in patients with chronic atrophic gastritis and stomach cancer, there was a decrease in the number of phagocytic monocytes relative to the control group. When studying the indicators of the monocytes, it was found that where there was a decrease in spontaneous CL from 454 c.u. and below, induced by CL from 1186 c.u. or lower in the patients in our study, early gastric cancer was diagnosed. The phagocytic activity of the monocytes in early gastric cancer was $34 \%$ and lower. The study revealed a decrease in the effectiveness of the immune response of the non-specific link to immunity in early gastric cancer.

In the study of lipid peroxidation and the antioxidant defense in patients with chronic atrophic gastritis and stomach cancer, an increase in malondialdehyde (MDA) was found in comparison with the control group $\left(\mathrm{p}_{1-2}=0.03 ; \mathrm{p}_{1-3}=0.001 ; \mathrm{p}_{2-3}=0.001\right)$ 
Table 2: Diagnostics of early gastric cancer associated with Helicobacter pylori infection

\begin{tabular}{|c|c|c|c|}
\hline Indicators & $\begin{array}{c}\text { Control group } \\
\qquad N=104\end{array}$ & $\begin{array}{c}\text { Patients with CAG } \\
\qquad \mathrm{N}=97\end{array}$ & $\begin{array}{c}\text { Patients with GC } \\
\qquad \mathrm{N}=98\end{array}$ \\
\hline $\mathrm{MDA} \mu \mathrm{mol} / 1 \mathrm{~g}$ protein & $\begin{array}{c}1.6 \\
{[0.96-2.24]}\end{array}$ & $\begin{array}{c}5.35 \\
{[4.1-15.3]} \\
\mathrm{p}_{1-2}=0.03\end{array}$ & $\begin{array}{c}64.7 \\
{[45.3-135.3]} \\
\mathrm{p}_{1-3}=0.001 ; \mathrm{p}_{2-3}=0.001\end{array}$ \\
\hline $\mathrm{SOD} \mathrm{u} / \mathrm{min} / 1 \mathrm{~g}$ protein & $\begin{array}{c}204.41 \\
{[151.05-250.3]}\end{array}$ & $\begin{array}{c}243.4 \\
{[161-269.8]}\end{array}$ & $\begin{array}{c}286.1 \\
{[195.4-290.5]}\end{array}$ \\
\hline $\begin{array}{l}\mathrm{CAT} \mu \mathrm{mol} / \mathrm{s} / 1 \mathrm{~g} \\
\text { protein }\end{array}$ & $\begin{array}{c}115,4 \\
{[0.16-0.49]}\end{array}$ & $\begin{array}{c}95.3 \\
{[0.1-0.31]}\end{array}$ & $\begin{array}{c}63.6 \\
{[41.2-68.3]} \\
\mathrm{p}_{1-3}=0,001 ; \mathrm{p}_{2-3}=0.001\end{array}$ \\
\hline $\begin{array}{l}\mathrm{GPO} \mu \mathrm{mol} / \mathrm{s} / 1 \mathrm{~g} \\
\text { protein }\end{array}$ & $\begin{array}{c}49.1 \\
{[81.19-162.38]}\end{array}$ & $\begin{array}{c}74.1 \\
{[70.1-104.05]} \\
\mathrm{p}_{1-2}=0.04\end{array}$ & $\begin{array}{c}68.1 \\
{[61.6-70.3]} \\
\mathrm{p}_{1-3}=0.001 ; \mathrm{p}_{2-3}=0.001\end{array}$ \\
\hline SOD/CAT & $1.77 \leq$ & $\begin{array}{l}2.55 \pm 1.25 \\
\mathrm{p}_{1-2}=0.04\end{array}$ & $\begin{array}{c}4.25 \geq \\
\mathrm{p}_{1-3}=0.001 ; \mathrm{p}_{2-3}=0.03\end{array}$ \\
\hline $\mathrm{SOD} / \mathrm{GPO}$ & $\geq 4.15$ & $\begin{array}{l}3.28 \pm 0.42 \\
\mathrm{p}_{1-2}=0.01\end{array}$ & $\begin{array}{c}2.8 \leq \\
\mathrm{p}_{1-3}=0.001 ; \mathrm{p}_{2-3}=0.04\end{array}$ \\
\hline
\end{tabular}

Note: $\mathbf{p}_{1-2}$ : statistically significant differences between the group of CAG patients and the control group, $\mathbf{p}_{1-3}$ : statistically significant differences between the group of patients with GC and the control group, $\mathbf{p}_{2-3}$ : statistically significant differences between the group of patients with CAG and the group of patients with GC.

(Table 2). In the patients with gastric cancer, there was a decrease in the enzyme catalase (CAT) activity compared with the group of patients with chronic atrophic gastritis and the control group $\left(\mathrm{p}_{1-3}=0.001\right.$; $\left.\mathrm{p}_{2-3}=0.001\right)$. In the patients with chronic atrophic gastritis, there was a decrease in glutathione peroxidase (GPO) compared with the control group $\left(\mathrm{p}_{1-2}=\right.$ $0.04)$. In the patients with early gastric cancer, an increase in the activity of the GPO enzyme was found relative to the control group and patients with chronic atrophic gastritis.

We have proposed coefficients for assessing the factors of the AOD system in patients, specifically the ratio of the activity of the enzyme superoxide dismutase to catalase (SOD/CAT) and the ratio of the activity of the enzyme superoxide dismutase to glutathione peroxidase (SOD/GPO). The proposed ratio of the activity of the enzyme superoxide dismutase to catalase (SOD/CAT) was 4.25 c.u. and it was higher in patients with early gastric cancer. The ratio of the activity of the enzyme superoxide dismutase to glutathione peroxidase (SOD/GPO) showed a value of 2.8 c.u. and it was lower in patients with early gastric cancer.

All of the threshold values for the maximum intensity of spontaneous (Ispont) and induced chemiluminescence (Iinduce) of the neutrophils and monocytes, the indices of granulocytic and monocytic phagocytosis, malondialdehyde (MDA), and the ratio of the activity of the enzyme superoxide dismutase to glutathione peroxidase (SOD / SOD GPO) were obtained empirically based on the analysis of the levels of the studied parameters in the patients with chronic atrophic gastritis and early gastric cancer relative to the control group.

Ispont (neutrophils) - 17825 c.u. and less $\mathrm{OR}=3.2$ $\left(95 \% \mathrm{CI}=1.27-27.3, \mathrm{p}_{1-2}=0.001\right)$

Ispont (monocytes) -419 c.u. and less $\mathrm{OR}=2.2(95 \%$ $\left.\mathrm{CI}=2.34-19.8, \mathrm{p}_{1-2}=0.0013\right)$

Iindust (neutrophils) - 24987 c.u and less OR $=1.7$ $\left(95 \% \mathrm{CI}=2.5-12.6, \mathrm{p}_{1-2}=0.0045\right)$

Iinduce (monocytes) $-962 \mathrm{c.u}$ and less $\mathrm{OR}=4.3$ $\left(95 \% \mathrm{CI}=4.6-15.3, \mathrm{p}_{1-2}=0.008\right)$

MDA $-45.3 \mu \mathrm{mol} / 1 \mathrm{~g}$ of protein or more $\mathrm{OR}=5.1$ $\left(95 \% \mathrm{CI}=1.72-53.3, \mathrm{p}_{1-2}=0.0017\right)$

SOD / CAT -4.25 or more OR $=1.9(95 \% \mathrm{CI}=2.57$

$\left.-9.12, \mathrm{p}_{1-2}=0.005\right)$

$\mathrm{SOD} / \mathrm{GPO}-2.8$ and below $\mathrm{OR}=2.2(95 \% \mathrm{CI}=0.72$

$\left.-0.93, \mathrm{p}_{1-2}=0.0023\right)$

Age (49-75 years) $\mathrm{OR}=3\left(95 \% \mathrm{CI}=2.1-12.0, \mathrm{p}_{1-2}\right.$ $=0.001$ )

The presence of concomitant diseases OR $=4.2(95 \%$ $\left.\mathrm{CI}=2.5-12.3, \mathrm{p}_{1-2}=0.001\right)$ 


\section{DISCUSSION}

In patients with early gastric cancer, the revealed changes are probably associated with infection by $\mathrm{He}$ licobacter pylori and its effect on the gastric mucosa ${ }^{19}$. By producing many enzymes for its metabolism, the microorganism launches histodestructive processes in the gastric mucosa, proving its virulence and carcinogenicity. The pathogenicity of Helicobacter pylori is due to its low susceptibility to antibiotic therapy ${ }^{20}$. An ineffective immune response retains Helicobacter pylori in the gastric mucosa 21 .

In the study of lipid peroxidation and the antioxidant defense in patients with chronic atrophic gastritis and stomach cancer, an increase in malondialdehyde (MDA) was found. In patients with gastric cancer, there was a decrease in the activity of the enzyme catalase (CAT). In patients with chronic atrophic gastritis, there was a decrease in glutathione peroxidase (GPO). In patients with early gastric cancer, an increase in the activity of the GPO enzyme was found relative to the control group and patients with chronic atrophic gastritis.

The proposed ratio of the activity of the enzyme superoxide dismutase to catalase (SOD/CAT) was 4.25 c.u. and it was higher in patients with early gastric cancer, which indicates the high activity of the enzyme superoxide dismutase and a decrease in the activity of the enzyme catalase as the disease progresses. The peroxides remaining in the superoxide dismutase reaction are not inactivated by an insufficient amount of catalase and they have a toxic and destructive effect on enterocytes of the gastric mucosa ${ }^{22}$. The ratio of the activity of the enzyme superoxide dismutase to glutathione peroxidase (SOD/GPO) showed a value of 2.8 c.u. and it was lower in patients with early gastric cancer. This indicates high activity for both enzymes, superoxide dismutase and glutathione peroxidase. The high activity of glutathione peroxidase, on the one hand, is probably due to an increase in the toxic manifestations from the tumor. On the other hand, a number of authors note the high activity of this enzyme alongside an increase in tumor resistance to chemotherapy ${ }^{23}$.

\section{CONCLUSIONS}

Our study has shown the significance of the following parameters: the maximum intensity of spontaneous (Ispont) and induced chemiluminescence (Iindus) of the neutrophils and monocytes, the indicators of granulocytic and monocytic phagocytosis, malondialdehyde (MDA), and the ratio of the activity of the enzyme superoxide dismutase to glutathione/CAT ratio superoxide dismutase to glutathione peroxidase (SOD/GPO) in the diagnosis of early gastric cancer. Using the threshold values of the proposed criteria in the screening of the adult population, it is possible to form a group of people who are at a high risk of developing early gastric cancer. This can help to achieve a decrease in the mortality and disability rates in the population of Siberia, as well as allowing for more personalized therapy for the patients at a high risk of developing early gastric cancer.

\section{ABBREVIATIONS}

CAG: chronic atrophic gastritis; CAT: catalase; CL: chemiluminescence; GPO: glutathione peroxidase; LPO: AOD system-antioxidant defense system; MDA: malondialdehyde; SOD: superoxide dismutase

\section{ACKNOWLEDGMENTS}

None.

\section{AUTHOR'S CONTRIBUTIONS}

Smirnova O.: statistical data processing, article editing, Sinyakov A.: collection of clinical material, statistical data processing, article writing. All authors read and approved the final manuscript.

\section{FUNDING}

The research was carried out at the expense of the state order of the Scientific Research Institute of Medical Problems of the North.

\section{AVAILABILITY OF DATA AND MATERIALS}

Data and materials used and/or analyzed during the current study are available from the corresponding author on reasonable request.

\section{ETHICS APPROVAL AND CONSENT TO PARTICIPATE}

This study was conducted in accordance with the amended Declaration of Helsinki. The institutional review board approved the study, and all participants provided written informed consent.

\section{CONSENT FOR PUBLICATION}

Not applicable.

\section{COMPETING INTERESTS}

The authors declare that they have no competing interests. 


\section{REFERENCES}

1. Fuchs CS, Mayer RJ. Gastric carcinoma. The New England Journal of Medicine. 1995;333(1):32-41. PMID: 7776992. Available from: 10.1056/NEJM199507063330107.

2. Bray F, Ferlay J, Soerjomataram I, Siegel RL, Torre LA, Jemal A. Global cancer statistics 2018: GLOBOCAN estimates of incidence and mortality worldwide for 36 cancers in 185 countries. CA: a Cancer Journal for Clinicians. 2018;68(6):394-424. PMID: 30207593. Available from: 10.3322/caac.21492.

3. Ferlay J, Soerjomataram I, Dikshit R, Eser S, Mathers C, Rebelo $M$. Cancer incidence and mortality worldwide: sources, methods and major patterns in GLOBOCAN 2012. International Journal of Cancer. 2015;136(5):359-86. PMID: 25220842. Available from: 10.1002/ijc.29210.

4. Yoshida Y, Sasako M, Kato H, Moriya Y. Bannasch P, editor. Early detection of gastrointestinal cancers: recent progress in endoscopy and surgical results. Berlin: Springer Verlag; 1992. Available from: 10.1007/978-3-642-76899-6_5.

5. Jemal A, Siegel R, Ward E, Murray T, Xu J, Thun MJ. Cancer statistics, 2007. CA: a Cancer Journal for Clinicians. 2007;57(1):43-66. PMID: 17237035. Available from: 10.3322/ canjclin.57.1.43.

6. Pasechnikov VD, Chukov SZ. Epidemiology of stomach cancer. Grew up zhurn gastroenterol, hepatol, coloproctol. 2002;3:18-26.

7. Tsuburaya A, Mizusawa J, Tanaka Y, Fukushima N, Nashimoto A, Sasako M, et al. Neoadjuvant chemotherapy with S-1 and cisplatin followed by D2 gastrectomy with para-aortic lymph node dissection for gastric cancer with extensive lymph node metastasis. British Journal of Surgery. 2014;101(6):653-60. PMID: 24668391. Available from: 10.1002/bjs.9484.

8. Sano T, Sasako M, Katai H, Maruyama K. Randomized controlled trials on adjuvant therapy for gastric cancer: Japanese experience. In: T Nakajima, T Yamaguchi, editors. Multimodality therapy for gastric cancer. Tokyo: Springer-Verlag; 1999. Available from: 10.1007/978-4-431-67927-1_2.

9. Allum WH, Powell DJ, McConkey CC, Fielding JW. Gastric cancer: a 25-year review. British Journal of Surgery. 1989;76(6):535-40. PMID: 2758258. Available from: 10.1002/ bjs. 1800760604 .

10. Fuccio L, Eusebi LH, Bazzoli F. Gastric cancer, Helicobacter pylori infection and other risk factors. World Journal of Gastrointestinal Oncology. 2010;2(9):342-7. PMID: 21160805. Available from: 10.4251/wjgo.v2.19.342.

11. Correa P. Chronic gastritis as a cancer precursor. Scandinavian Journal of Gastroenterology Supplement. 1984;104:1316. PMID: 6597545.

12. Pimentel-Nunes $P$, Libânio $D$, Lage J, Abrantes $D$, Coimbra $M$, Esposito G. A multicenter prospective study of the real-time use of narrow-band imaging in the diagnosis of premalignant gastric conditions and lesions. Endoscopy. 2016;48(8):723-30.
PMID: 27280384. Available from: 10.1055/s-0042-108435.

13. Kikuste I, Marques-Pereira R, Monteiro-Soares M, PimentelNunes $P$, Areia M, Leja M. Systematic review of the diagnosis of gastric premalignant conditions and neoplasia with highresolution endoscopic technologies. Scandinavian Journal of Gastroenterology. 2013;48(10):1108-17. PMID: 24047392. Available from: 10.3109/00365521.2013.825315.

14. Soer EC, Leicher LW, Langers AM, van de Meeberg PC, van der Wouden EJ, Koornstra JJ. Equivalent Helicobacter pylori infection rates in Lynch syndrome mutation carriers with and without a first-degree relative with gastric cancer. International Journal of Colorectal Disease. 2016;31(3):693-7. PMID: 26847620. Available from: 10.1007/s00384-016-2524-7.

15. Hamashima C, Group SR, for Gastric Cancer Screening Guidelines GDG. Update version of the Japanese Guidelines for gastric cancer screening. Japanese Journal of Clinical Oncology. 2018;48(7):673-83. PMID: 29889263. Available from: $10.1093 / \mathrm{jjco} / \mathrm{hyy} 077$.

16. Choi JM, Kim SG, Choi J, Park JY, Oh S, Yang HJ, et al. Effects of Helicobacter pylori eradication for metachronous gastric cancer prevention: a randomized controlled trial. Gastrointestinal Endoscopy. 2018;88(3):475-485. PMID: 29800546. Available from: 10.1016/j.gie.2018.05.009.

17. Kato M, Asaka M. Recent development of gastric cancer prevention. Japanese Journal of Clinical Oncology. 2012;42(11):987-94. PMID: 23018579. Available from: 10 . 1093/jjco/hys151.

18. Nomura AM, Lee J, Stemmermann GN, Nomura RY, PerezPerez Gl, Blaser MJ. Helicobacter pylori CagA seropositivity and gastric carcinoma risk in a Japanese American population. The Journal of Infectious Diseases. 2002;186(8):1138-44. PMID: 12355365. Available from: 10.1086/343808.

19. Wroblewski LE, Peek RM, Wilson KT. Helicobacter pylori and gastric cancer: factors that modulate disease risk. Clinical Microbiology Reviews. 2010;23(4):713-39. PMID: 20930071. Available from: 10.1128/CMR.00011-10.

20. Wu W, Yang Y, Sun G. Recent Insights into Antibiotic Resistance in Helicobacter pylori Eradication. Gastroenterology Research and Practice. 2012;2012:723183. PMID: 22829809. Available from: 10.1155/2012/723183.

21. Galiatsatos P, Wyse J, Szilagyi A. Accuracy of biopsies for Helicobacter pylori in the presence of intestinal metaplasia of the stomach. The Turkish Journal of Gastroenterology. 2014;25(1):19-23. PMID: 24918125. Available from: 10.5152/ tjg.2014.6476.

22. Pushkin TA, Tokaev ES, Popova TS, Borodin EN. Superoxide dismutase as part of antioxidant therapy: state of the art and prospects (literature review). Emergency medical care. Journal named after N.V. Sklifosovsky. 2016;4:42-7.

23. Borunov EV, Smirnova LP, Shchepetkin IA, et al. High activity of antioxidant enzymes as a factor in avoiding control of the immune system. Bul expert biol honey. 1989;4:41-43. 
Ready to submit your manuscript? Choose Biomedpress and benefit from:

- Fast, convenient online submission

- Through peer-review by experienced researchers

- Rapid publication on acceptance

- Free of charge (without publication fees)

Learn more http://www.biomedpress.org/journals/
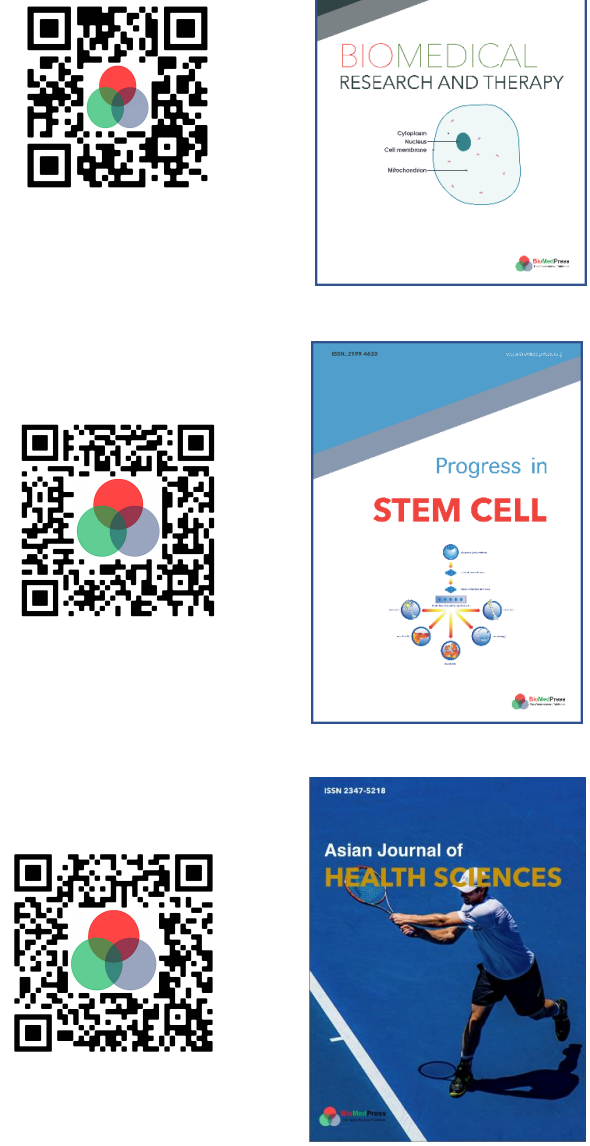

Asian Journal of Health Sciences

ISSN: 2347-5218

Indexed: Google Scholar

Acceptance Rate (2020): 72.89\%

Article Publishing Charge: Free

Submission to first editorial decision: 16.5 days

Biotechnological Research

ISSN: 2395-6763

Indexed: Google Scholar

Acceptance Rate (2020): $67.02 \%$

Article Publishing Charge: Free

Submission to first editorial decision: 28.5 days 